\title{
Editorial for the Special Issue AMP
}

\author{
Djamel Drider
}

Published online: 27 February 2010

(C) Springer Science + Business Media, LLC 2010

I would like to take this opportunity to express my sincere gratitude to Springer for allowing us to publish in "Probiotics and Antimicrobial Proteins" part of the main conferences of the 2nd International Symposium on Antimicrobial Peptides: Food, Veterinary, Medical, and Novel Applications, which took place in Saint-Malo (France) from June 17-19, 2009. The organizers and scientific committees also wish to restate their acknowledgments for the institutions (Ecole Nationale d'Ingénieurs des Techniques des Industries Agricoles et Alimentaires, Nantes, France; and the French Agency for Food Safety, Ploufragan, France), local authorities (Régions des Pays de la Loire et de Bretagne), and industries who provided financial support.

The AMP2009 symposium permitted 200 attendees from 23 countries to interact during three working days and share their experience with academic and applied research devoted to antimicrobial peptides. AMP2009 was also an excellent opportunity for young and emerging scientists to present their projects through posters, oral presentations and scientific discussions with renowned scientists. As cochairman of AMP2009 and the founder of this conference, I am so happy and proud to see the increasingly international dimension taken on by this scientific event, which clearly shows that antimicrobial peptides are still of major interest and remain a promising, open avenue of research.

To date, thousands of antimicrobial peptides from prokaryotic, fungal, plant and animal sources have been identified; their potential as novel therapeutic agents for the treatment of infection, stimulation of the immune system or countering of septic shock has been widely recognized.

D. Drider $(\square)$

Nantes Cedex 3, France

e-mail: drider@enitiaa-nantes.fr
Many peptides are now tracked in Antimicrobial Sequence Databases such as http://www.bbcm.units.it/ tossi/pag1. htm, http://aps.unmc.edu/AP/main.html, http://defensins. bii.a-star.edu.sg/, and http://faculty.ist.unomaha.edu/chen/ rapd/index.php. The development of novel antimicrobial peptides has gained widespread attention in response to the phenomenon of bacterial multi-drug resistance, which has become a public health major concern in human and veterinary medicine, as well as in food production. Indeed, as soon as antibiotics were introduced as therapies, bacteria began to resist their activity by developing mechanisms of resistance that help them to evade their toxic effects. The large amount of antibiotics used through the past decades in human and animal medications has resulted in the selection of pathogenic bacteria resistant to multiple drugs. Resistance has been observed with every antimicrobial; the only observable difference between drugs has been the time required for such resistance to emerge. The response of the scientific community and various industries to this threatening situation must be swift yet appropriate. Our knowledge is continuously updated through the discovery of novel and effective molecules, especially antimicrobial peptides, whose isolation from unexplored sources can be anticipated using smart screening technologies. The next generation of antimicrobial peptides (hybrid peptides, congener peptides, stabilized peptides, conjugated peptides and immobilized peptides) may also be designed and engineered.

I truly believe that this conference will continue to attract more and more participants in the future by organizing outstanding scientific programmes and committees of the highest caliber. In closing, I am pleased to announce that the third gathering of this conference has been scheduled for June 2012. 